NASA/CR-1998-208670

ICOMP-98-05
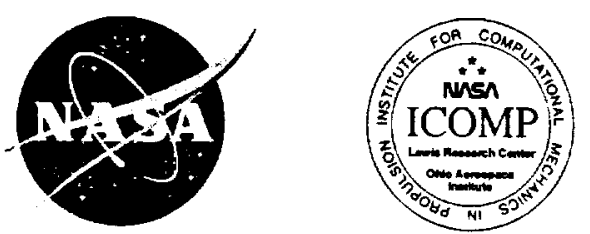

NN-64

432195

Nonlinear Comparison of High-Order and Optimized Finite-Difference Schemes

R. Hixon

Institute for Computational Mechanics in Propulsion, Cleveland, Ohio 
Since its founding, NASA has been dedicated to the advancement of aeronautics and space science. The NASA Scientific and Technical Information (STI) Program Office plays a key part in helping NASA maintain this important role.

The NASA STI Program Office is operated by Langley Research Center, the Lead Center for NASA's scientific and technical information. The NASA STI Program Office provides access to the NASA STI Database, the largest collection of aeronautical and space science STI in the world. The Program Office is also NASA's institutional mechanism for disseminating the results of its research and development activities. These results are published by NASA in the NASA STI Report Series, which includes the following report types:

- TECHNICAL PUBLICATION. Reports of completed research or a major significant phase of research that present the results of NASA programs and include extensive data or theoretical analysis. Includes compilations of significant scientific and technical data and information deemed to be of continuing reference value. NASA's counterpart of peerreviewed formal professional papers but has less stringent limitations on manuscript length and extent of graphic presentations.

- TECHNICAL MEMORANDUM. Scientific and technical findings that are preliminary or of specialized interest, e.g., quick release reports, working papers, and bibliographies that contain minimal annotation. Does not contain extensive analysis.

- CONTRACTOR REPORT. Scientific and technical findings by NASA-sponsored contractors and grantees.
- CONFERENCE PUBLICATION. Collected papers from scientific and technical conferences, symposia, seminars, or other meetings sponsored or cosponsored by NASA.

- SPECIAL PUBLICATION. Scientific, technical, or historical information from NASA programs, projects, and missions, often concerned with subjects having substantial public interest.

- TECHNICAL TRANSLATION. Englishlanguage translations of foreign scientific and technical material pertinent to NASA's mission.

Specialized services that complement the STI Program Office's diverse offerings include creating custom thesauri, building customized data bases, organizing and publishing research results ... even providing videos.

For more information about the NASA STI Program Office, see the following:

- Access the NASA STI Program Home Page at http://www.sti.nasa.gov

- E-mail your question via the Internet to help@sti.nasa.gov

- Fax your question to the NASA Access Help Desk at (301) 621-0134

- Telephone the NASA Access Help Desk at (301) 621-0390

- Write to: NASA Access Help Desk NASA Center for AeroSpace Information 7121 Standard Drive Hanover, MD 21076 

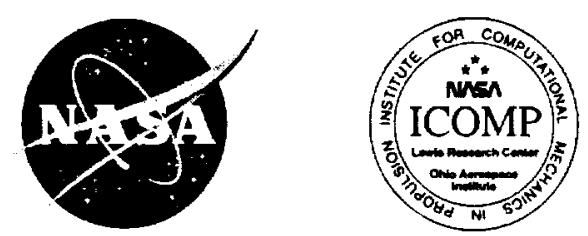

\section{Nonlinear Comparison of High-Order and Optimized Finite-Difference Schemes}

R. Hixon

Institute for Computational Mechanics in Propulsion, Cleveland, Ohio

Prepared urider Cooperative Agreement NCC3-531

National Aeronautics and

Space Administration

Lewis Research Center 


\section{Acknowledgments}

This work was carried out under grant NCC3-531 from the NASA Lewis Research Center. while the author was in residence at the Institute of Computational Mechanics in Propulsion, located at the Ohio Aerospace Institute. Dr. L.A. Povinelli was the Technical Monitor.

Available from

NASA Center for Aerospace Information 7121 Standard Drive

Hanover, MD 21076

Price Code: A03
National Technical Information Service 5285 Port Royal Road Springfield, VA 22100 Price Code: A03 


\title{
NONLINEAR COMPARISON OF HIGH-ORDER AND OPTIMIZED FINITE-DIFFERENCE SCHEMES
}

\author{
R. Hixon \\ Institute for Computational Mechanics in Propulsion (ICOMP) \\ NASA Lewis Research Center, Cleveland, $\mathrm{OH} 44135$
}

\begin{abstract}
$\underline{\text { Abstract }}$
The effect of reducing the formal order of accuracy of a finite-difference scheme in order to optimize its high-frequency performance is investigated using the 1-D nonlinear unsteady inviscid Burgers' equation. It is found that the benefits of optimization do carry over into nonlinear applications. Both explicit and compact schemes are compared to Tam and Webb's explicit 7-point Dispersion Relation Preserving scheme as well as a Spectral-like compact scheme derived following Lele's work. Results are given for the absolute and L2 errors as a function of time.
\end{abstract}

\section{Introduction}

Computational aeroacoustics is concerned with the time-accurate solution of flow and acoustic phenomena over long periods of time. To accomplish this goal, high-order finite-difference schemes and optimized schemes have been developed [e.g., Refs 1-8].

There are two main classes of high-accuracy finite-difference schemes: explicit schemes and compact schemes. Explicit schemes employ large computational stencils for accuracy, while compact schemes use smaller stencils by using the flux derivatives as independent variables at each grid point. While compact schemes are more accurate than the equivalent explicit scheme, solving 
for each flux derivative requires a scalar tridiagonal or pentadiagonal matrix inversion ${ }^{1}$. Recently, however, an new prefactorization method has been introduced that allows the matrices to be prefactored into two easier to solve matrices ${ }^{7,8}$.

There are also two strategies for designing finite-difference stencils. For a given stencil, one can either choose coefficients that return the highest formal order of accuracy possible, or the stencil can be optimized to reduce high-frequency errors at the price of lowering the formal order of accuracy. This optimization work has been used for both compact $^{1}$ and explicit ${ }^{3}$ stencils.

In this work, the nonlinear performance of optimized schemes will be investigated using the 1D unsteady Burgers' equation.

\section{Mathematical and Numerical Formulation}

Given a function $f(x)$, a general finite-difference central derivative at grid point $\mathbf{n}$ can be written as:

$$
\left(\frac{d f}{d x}\right)_{n}+\text { Error }+\sum_{j=1}^{N J} b_{j}\left[\left(\frac{d f}{d x}\right)_{n-j}+\left(\frac{d f}{d x}\right)_{n+j}\right]=\sum_{i=1}^{N I} a_{i}\left[f_{n+i}-f_{n-i}\right]
$$

The right-hand-side of Eq. (1) determines if the differencing scheme is explicit or compact. For a compact differencing scheme, each derivative depends on the value of its neighboring derivatives; thus, a scalar matrix inversion is required to obtain the values of the derivatives. For an explicit differencing scheme, however, the value of each derivative is independent of its neighbors.

The error term is a function of the order of accuracy of the scheme. To estimate the magnitude 
of the error, we follow the work of Lele ${ }^{1}$ and Tam and $\mathrm{Webb}^{3}$. Let us assume that the function we are taking the numerical derivative of is a sine wave of period one:

$$
\begin{aligned}
& f=\sin (2 \pi x) \\
& \frac{d f}{d x}=2 \pi \cos (2 \pi x)
\end{aligned}
$$

where $-0.5<x<0.5$. We have a given number of points per wavelength:

$$
\Delta x=\frac{1}{P P W}
$$

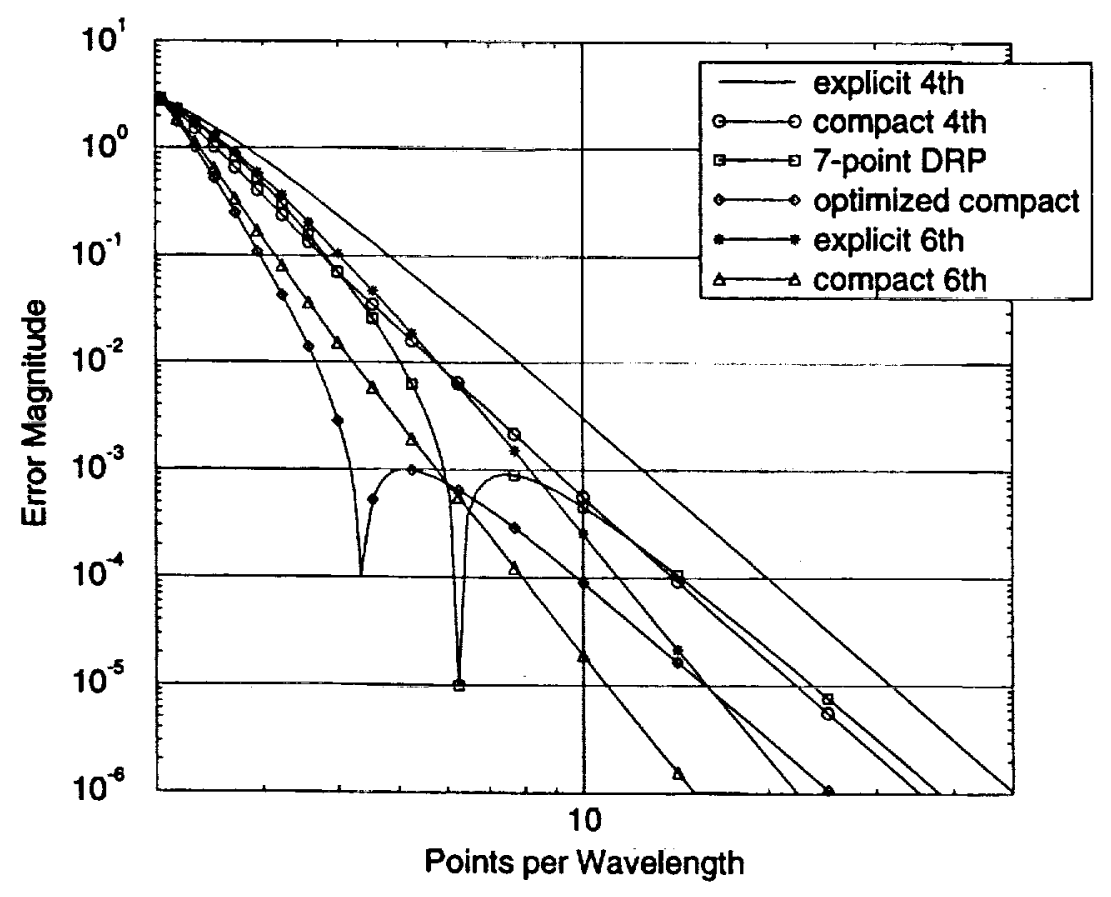

Figure 1: Error Magnitude as a Function of Points Per Wavelength for Finite-Difference Derivatives 
Thus, the function at the grid points can be written as:

$$
f_{i}=\sin (2 \pi i \Delta x)
$$

and the numerical derivative at $\mathrm{x}=0$ becomes:

$$
\left(\frac{d f}{d x}\right)_{0}+E r r o r+\sum_{j=1}^{N J} b_{j}\left[\left(\frac{d f}{d x}\right)_{-j}+\left(\frac{d f}{d x}\right)_{j}\right]=\sum_{i=1}^{N I} 2 a_{i} \sin (2 \pi i \Delta x)
$$

The coefficients for the schemes investigated are given in Table 1 .

The error in a central derivative is dispersive, and the numerical derivative takes the form:

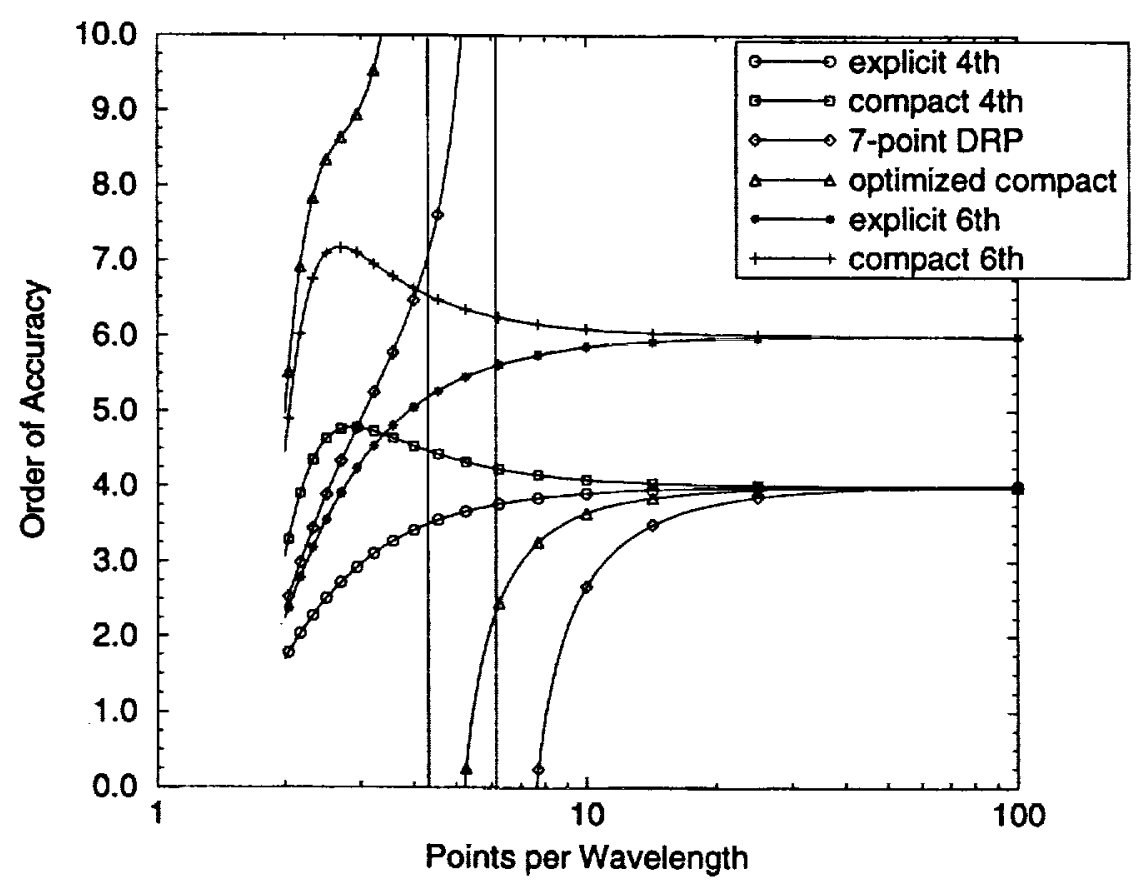

Figure 2: Order of Accuracy as a Function of Points Per Wavelength for Finite-Difference Derivatives 


$$
\frac{d}{d x} \sin (2 \pi x)=2 \pi(1-\varepsilon) \cos (2 \pi x)
$$

Using this definition, the derivative at $\mathrm{x}=0$ can be written as:

$$
2 \pi(1-\varepsilon)\left(1+\sum_{j=1}^{N J} 2 b_{j}[\cos (2 \pi i \Delta x)]\right)=\sum_{i=1}^{N I} 2 a_{i} \sin (2 \pi i \Delta x)
$$

The error at $x=0$ can then be written as:

$$
\text { Error }=2 \pi \varepsilon=\frac{\sum_{i=1}^{N I} 2 a_{i} \sin (2 \pi i \Delta x)}{\left(1+\sum_{j=1}^{N J} 2 b_{j}[\cos (2 \pi i \Delta x)]\right)}
$$

Table 1: Finite-Difference Scheme Coefficients

\begin{tabular}{|c|c|c|c|c|c|}
\hline Scheme & $b_{1}$ & $a_{1}$ & $a_{2}$ & $a_{3}$ & $\begin{array}{c}\text { Order of } \\
\text { accuracy }\end{array}$ \\
\hline \hline explicit 4 & 0 & $2 / 3$ & $1 / 12$ & 0 & 4 \\
\hline $\begin{array}{c}7 \text {-point } \\
\text { DRP }\end{array}$ & 0 & 0.7708824 & -0.1667059 & 0.0208431 & 4 \\
\hline explicit 6 & 0 & $3 / 4$ & $-3 / 20$ & $1 / 60$ & 6 \\
\hline compact 4 & $1 / 4$ & $3 / 4$ & 0 & 0 & 4 \\
\hline $\begin{array}{c}\text { optimized } \\
\text { compact }\end{array}$ & 0.35196 & 0.7839867 & 0.0339867 & 0 & 4 \\
\hline compact 6 & $1 / 3$ & $7 / 9$ & $1 / 36$ & 0 & 6 \\
\hline
\end{tabular}


Figure 1 shows the error magnitude as a function of the number of points per wavelength. Notice the wide range of errors for different schemes even though they have the same order of accuracy. Figure 2 shows the order of accuracy as a function of the number of points per wavelength. Notice that it requires $25-40$ points per wavelength for the schemes to settle to their formal order of accuracy. In practice, this many points cannot be used due to computer limitations.

In Fig. 1, the two optimized schemes show similar error curves. The effect of the optimization is to increase the resolution of the scheme with few points per wavelength by lowering the formal order of accuracy, and hence reducing the performance of the scheme with many points per wavelength. The curves in Fig. 1 show that the optimized schemes always perform better than the unoptimized scheme of the same order of accuracy (while also requiring more work). The curves also show that there is a range where the optimized scheme will be more accurate than a higherorder scheme using the same stencil, but this range is fairly limited.

For a linear problem with a small range of frequencies, the optimized scheme can be made to outperform the higher-order scheme. However, with a change in grid spacing, the higher-order scheme can also be made to outperform the optimized scheme. As the frequency range increases, it becomes less clear which scheme provides a better solution.

In an umsteady nonlinear problem, however, the frequency range changes as time progresses. An example of a nonlinear equation is the inviscid 1-D Burgers' equation:

$$
\frac{\partial u}{\partial t}+\frac{\partial}{\partial x}\left(\frac{1}{2} u^{2}\right)=0
$$


Given an initial single-frequency periodic solution on the domain $0<x<1$ :

$$
u(x, 0)=c_{0}+A \sin (2 \pi x),
$$

the solution can be written as:

$$
u(x, t)=u(\xi, 0)=c_{0}+A \sin (2 \pi \xi)
$$

where

$$
\begin{aligned}
& \xi=x-u t \\
& 0 \leq \xi \leq 1
\end{aligned}
$$

However, at time:

$$
t=\frac{1}{2 \pi A}
$$

a shock forms as the wave steepens, and the shock is located using Whitham's area rule?:

$$
t=\frac{\theta}{2 \pi A \sin \theta}
$$




$$
\begin{gathered}
\xi_{1}=\frac{1}{2}\left(\frac{\theta}{\pi}+1\right) \\
\xi_{2}=\frac{1}{2}\left(1-\frac{\theta}{\pi}\right) \\
u_{1}=c_{0}+A \sin \left(2 \pi \xi_{1}\right) \\
u_{2}=c_{0}+A \sin \left(2 \pi \xi_{2}\right)
\end{gathered}
$$

The remaining part of the solution is found using Eq. (11).

Figure 3 shows a solution of Burgers' equation, with the initial condition:

$$
u(x, 0)=\frac{3}{4}+\frac{1}{4} \sin (2 \pi x)
$$

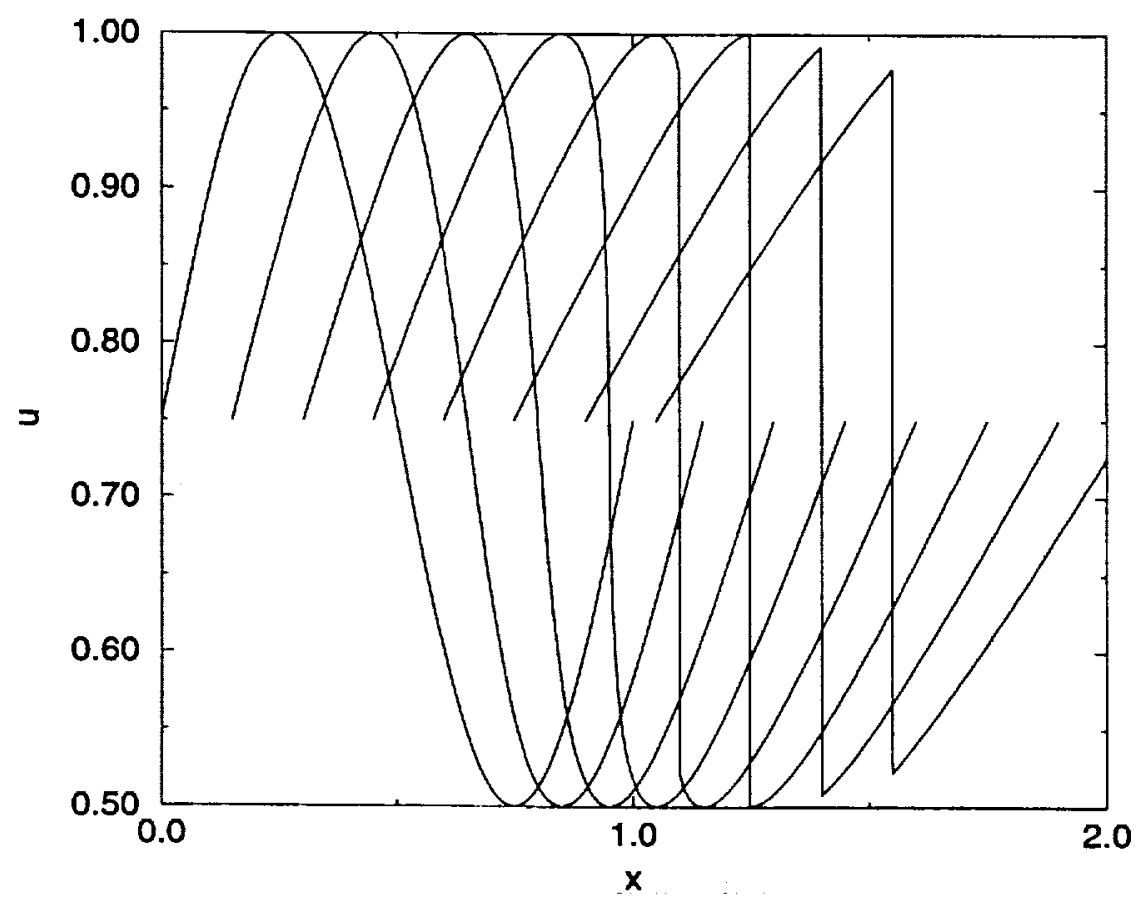

Figure 3: Solution of 1-D Nonlinear Burgers' Equation With Single-Frequency Input 
In this solution, the wave steepens as it travels, forming a shock at time $=0.637$. As time proceeds, the lower-frequency waves transfer more and more energy to the high-frequency waves, as illustrated in Fig. 4.

Since this is the inviscid Burgers' equation, the shock has no thickness. This means that there is no upper limit to the frequencies in the solution once the shock appears. Numerically, this means that there is no grid spacing that will resolve the shock.

Since this equation allows unlimited frequency growth and has an exact solution, it was used to compare the nonlinear performance of the six schemes given in Table 1.

\section{Numerical Test Description}

Two numerical tests will be shown. Test 1 has the initial distribution:

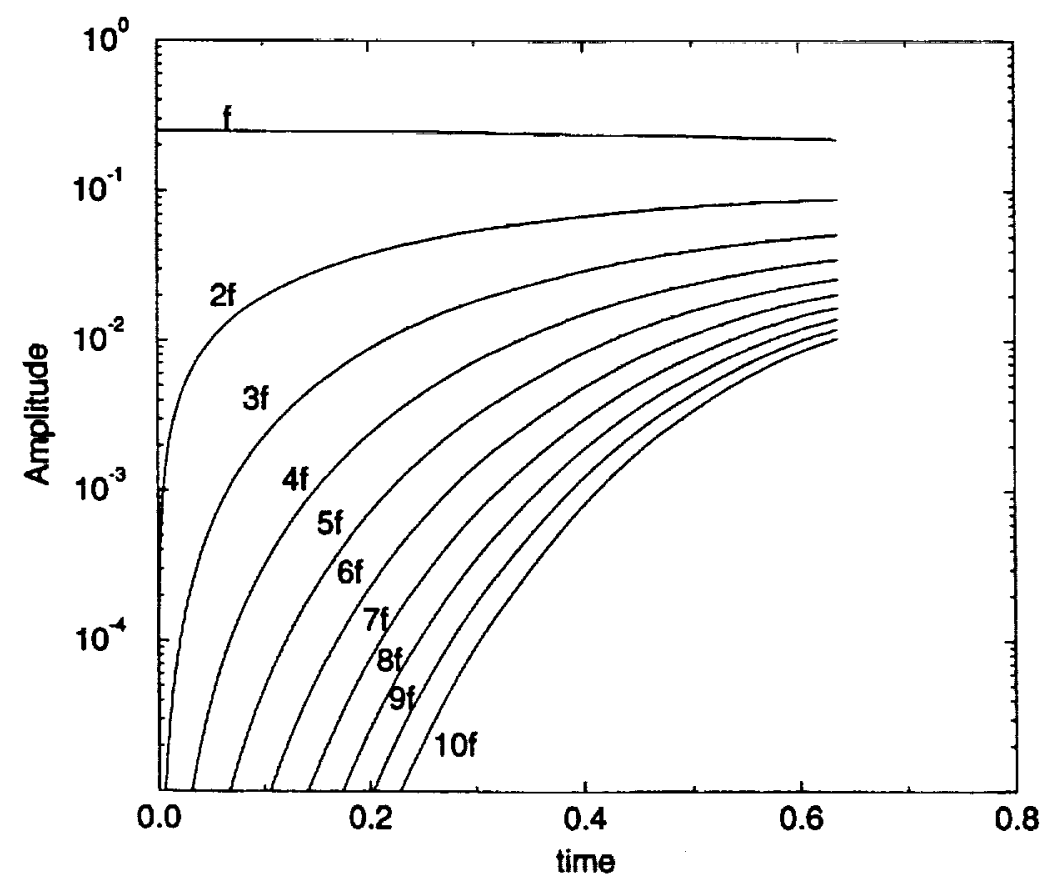

Figure 4: Frequency Content as a Function of Time for Solution of Burgers' Equation 


$$
u(x, 0)=\frac{3}{4}+\frac{1}{4} \sin (2 \pi x)
$$

while Test 2 has the initial distribution:

$$
u(x, 0)=\frac{3}{4}+\frac{1}{40} \sin (2 \pi x)
$$

In Test 2 , the lower amplitude of the sine wave reduces the rate of growth of the high-frequency modes, causing the wave to steepen more slowly. This lesser rate of nonlinearity will allow more time for any advantages of optimization to be shown before the high-frequency waves move into the unresolved range.

The grid for this problem has 24 equally spaced points, giving 24 points per wavelength for the initial wave. From Fig. 2, this corresponds roughly to the minimum number of points for each scheme to obtain its formal order of accuracy. This is also more than the number of points usually used for linear wave propagation in computational aeroacoustics calculations. The domain is periodic in order to remove the effect of boundary stencils and boundary condition specification from the results. The periodic domain may favor the compact schemes more than the explicit schemes, due to the effects of boundary stencil specifications on compact schemes ${ }^{10}$.

The time stepping method used is Stanescu and Habashi's ${ }^{11}$ fourth-order nonlinear extension of Hu's 5-6 optimized Runge-Kutta method ${ }^{12}$. The time step used is CFL $=0.025$. The small time step is used to ensure that the error is from the spatial discretization and not the time marching scheme. 
The compact differences are prefactored using Hixon and Turkel's method ${ }^{7}$, and calculated using the method described by Hixon ${ }^{8}$. The forward and backward stencils for the optimized compact scheme are given as:

$$
\begin{aligned}
& (1-\alpha) D_{i}^{F}+\alpha D_{i+1}^{F}=\beta f_{i+1}+(1-2 \beta) f_{i}+(\beta-1) f_{i-1} \\
& (1-\alpha) D_{i}^{B}+\alpha D_{i-1}^{B}=(1-\beta) f_{i+1}+(2 \beta-1) f_{i}-\beta f_{i-1}
\end{aligned}
$$

where

$$
\begin{aligned}
& \alpha=0.29157494 \\
& \beta=0.86318328
\end{aligned}
$$

\section{$\underline{\text { Results }}$}

Calculations were performed for Tests 1 and 2. No filtering or artificial dissipation terms were added; while the solutions would be improved by filtering out unresolved frequencies, it was found that the error due to the filtering overwhelmed the errors from the schemes as the shock formed. The reason was that the 10th and 12th order explicit filters that were tested damped high frequency components of the solution that the more accurate compact schemes could resolve.

Results are shown for the error amplitude as a function of time for each numerical scheme. Both the $\mathrm{L}_{2}$ and $\max$ error norms are shown. It was found that the max norm favored the optimized schemes, while the $\mathrm{L}_{2}$ norm was weighted more toward the high-order schemes. Since the $\mathrm{L}_{2}$ norm contains both the low-frequency and high-frequency error components, it was considered to be the more accurate measure of error for this problem. 


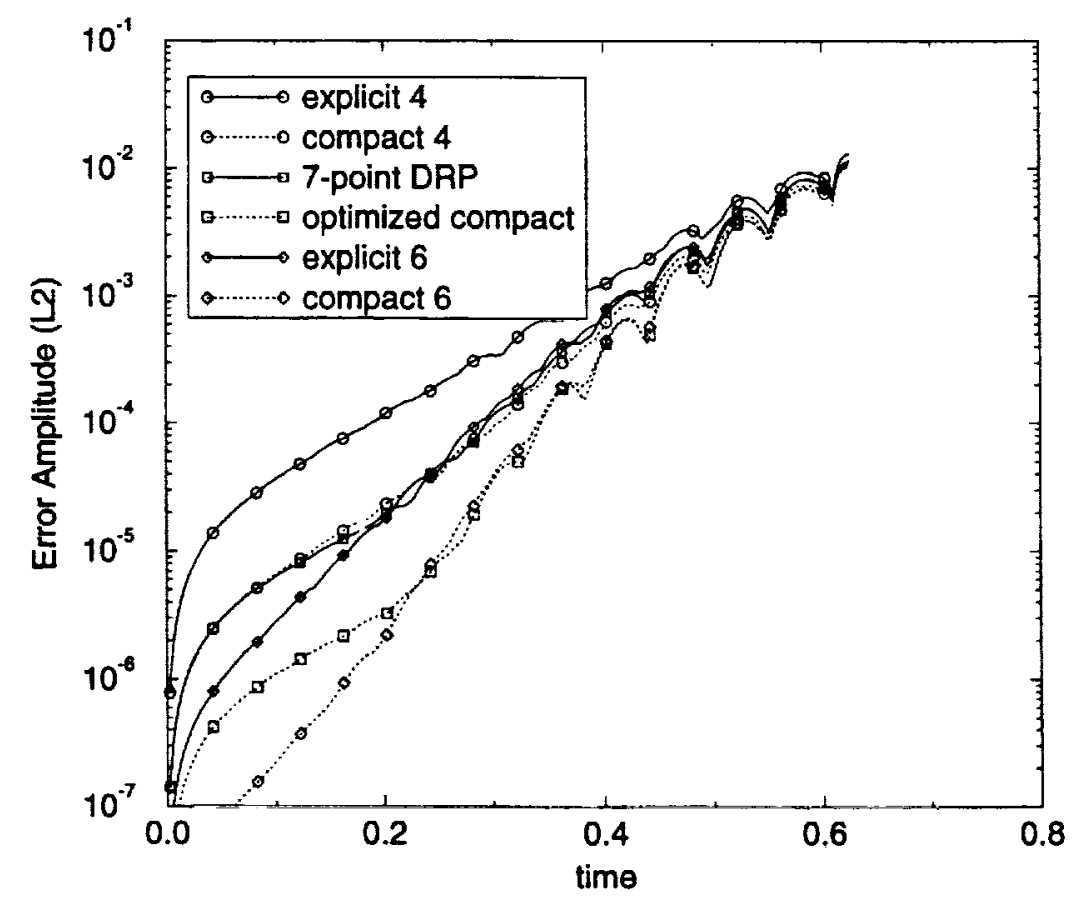

Figure 5: Time History of the L2 Norm Error Amplitude for Test Input 1

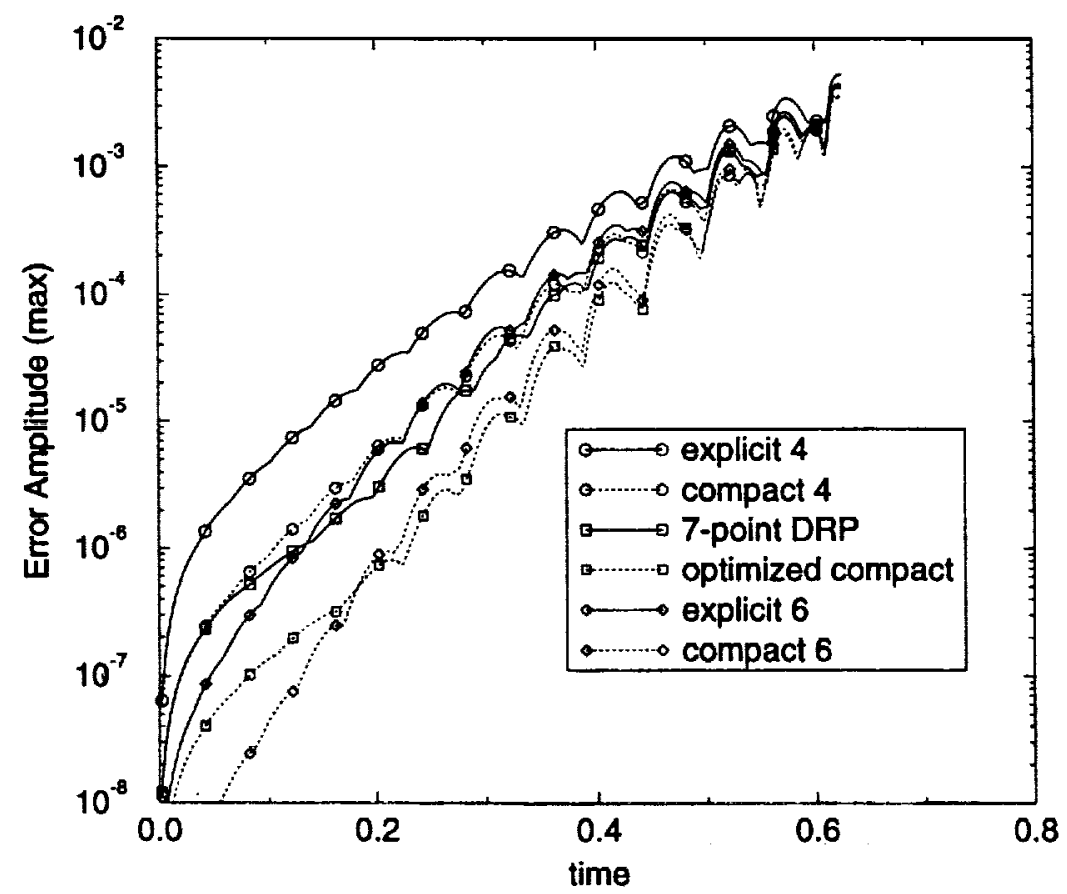

Figure 6: Time History of the Max Norm Error Amplitude for Test Input 1 


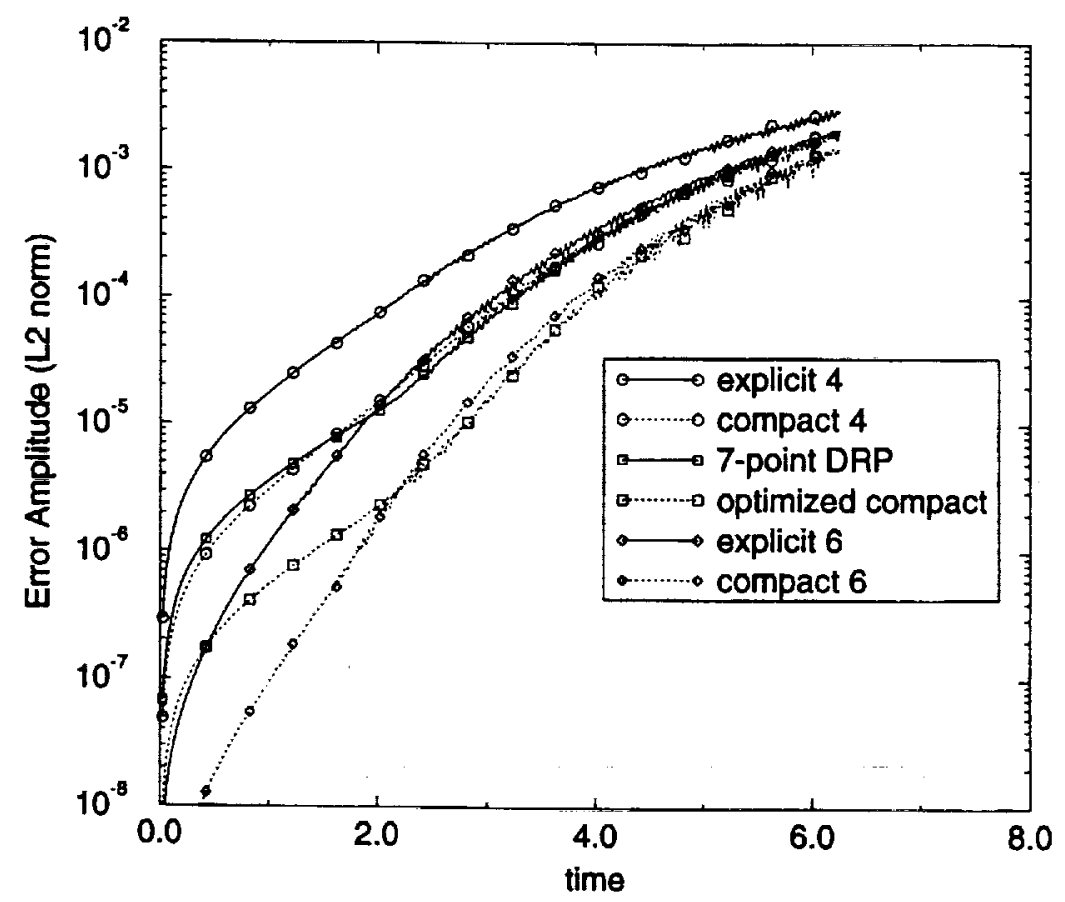

Figure 7: Time History of the L2 Norm Error Amplitude for Test Input 2

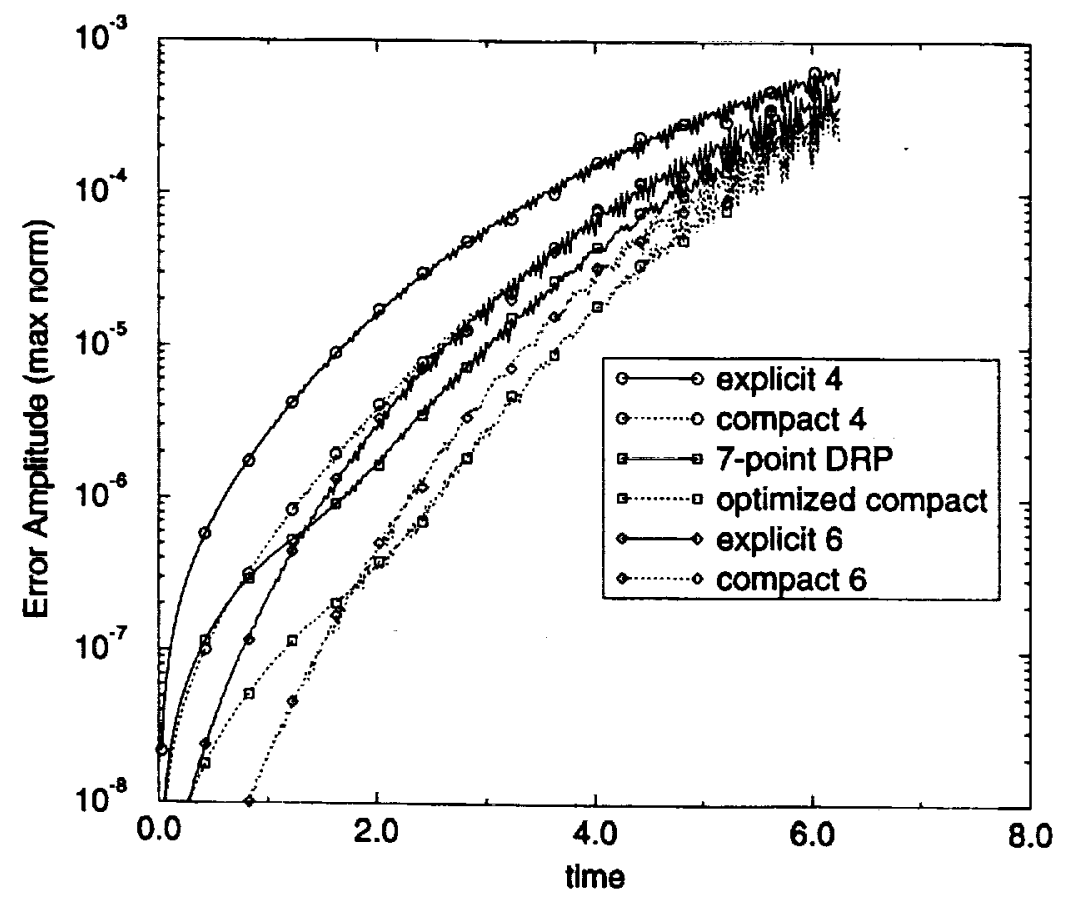

Figure 8: Time History of the Max Norm Error Amplitude for Test Input 2 
Figures 5 and 6 show the error time history for Test 1. In both figures, we see the initial advantages of the high-order schemes. However, at time $=0.2$, the wave has steepened to a point that high-frequency components of the solution exist. After this point, the optimized schemes perform equal to or slightly better than the high-order schemes with the same stencil size. This is more apparent using the max norm of error, but also is shown in the $\mathrm{L}_{2}$ norm of the error.

Figures 7 and 8 show the error time history for Test 2 . Notice that the shock takes much longer to form in this test. In Figs. 7 and 8, the same behavior is shown as in Test 1, with the optimized schemes showing more error reduction. This is due to the slower growth of high-frequency components in this test. Figure 8 shows that the max error norm is significantly lower with the optimized schemes, while Fig. 7 shows that the improvement is still seen in the $L_{2}$ norm results.

\section{Conclusions}

A nonlinear comparison of optimized and high-order finite-difference schemes has been performed using the 1-D inviscid Burgers' equation. From these simple tests, several conclusions can be drawn.

First, the compact schemes perform better than the explicit schemes, usually giving an order of magnitude reduction in the errors.

Second, the formal order of accuracy of a scheme is much less important than its performance at marginal resolution. Again, this is shown by the performance of the compact schemes and optimized schemes for these test problems.

Third, in most realistic nonlinear calculations, there will be areas of marginal resolution in the

grid. The error due to these areas will dominate the error in the solution. The improved performance of the optimized schemes at marginal resolution can more than compensate for the slightly 
increased error in fully resolved regions.

In summary, while these results are necessarily not general, they do indicate that the optimized schemes show an advantage for nonlinear problems as well as linear problems due to their improved performance at marginal resolution. Since the high-frequency waves are the major source of error, the gain from optimization more than offsets the loss of formal accuracy for both explicit and compact differencing schemes in these tests.

\section{Acknowledgment}

This work was carried out under grant NCC3-531 from the NASA Lewis Research Center while the author was in residence at the Institute for Computational Mechanics in Propulsion, located at the Ohio Aerospace Institute. Dr. L. A. Povinelli was the Technical Monitor.

\section{References}

1) Lele, S. K., 'Compact Finite Difference Schemes with Spectral-like Resolution', Journal of Computational Physics, Vol. 103, 1992, p. 16-42.

2) Haras, Z. and Ta'asan, S., 'Finite-Difference Schemes for Long-Time Integration', J. Comp. Physics, Vol. 114, 1994, pp. 265-279.

3) Tam, C. K. W. and Webb, J. C., 'Dispersion-Relation-Preserving Finite Difference Schemes for Computational Acoustics', J. Comp. Physics, Vol. 107, 1993, p. 262-281.

4) Zingg, D. W., Lomax, H., and Jurgens, H. M., 'An Optimized Finite-Difference Scheme for Wave Propagation Problems', AIAA Paper 93-0459, Jan. 1993.

5) Gottlieb, D. and Turkel, E., 'Dissipative Two-Four Method for Time Dependent Problems', Mathematics of Computation, Vol. 30, No. 136, 1976, p.703-723. 
6) Hixon, R., 'On Increasing the Accuracy of MacCormack Schemes for Aeroacoustic Applications', AIAA Paper 97-1586, Atlanta, GA, May 1997.

7) Hixon, R. and Turkel, E., 'High-Accuracy Compact MacCormack-Type Schemes for Computational Aeroacoustics', AIAA Paper 98-0365, Reno, NV, Jan. 1998.

8) Hixon, R., 'A New Class of Compact Schemes', AIAA Paper 98-0367, Reno, NV, Jan. 1998.

9) Whitham, G. B., Linear and Nonlinear Waves, John Wiley and Sons, New York, 1974.

10) Carpenter, M. H., Gottlieb, D., and Abarbanel, S., 'Stable and Accurate Boundary Treatments for Compact, High-Order Finite-Difference Schemes', Applied Numerical Mathematics, Vol. 12, 1993, pp. 55-87

11) Stanescu, D. and Habashi, W. G., '2N-Storage Low Dissipation and Dispersion Runge-Kutta Schemes for Computational Acoustics', to appear in J. Comp. Phys..

12) Hu, F. Q., Hussaini, M. Y., and Manthey, J., 'Low-Dissipation and -Dispersion Runge-Kutta Schemes for Computational Acoustics', ICASE Report 94-102, Dec. 1994. 


\begin{tabular}{|c|c|c|c|c|}
\hline \multicolumn{3}{|c|}{ REPORT DOCUMENTATION PAGE } & & $\begin{array}{l}\text { Form Approved } \\
\text { OMB No. } 0704-0188\end{array}$ \\
\hline \multicolumn{5}{|c|}{ 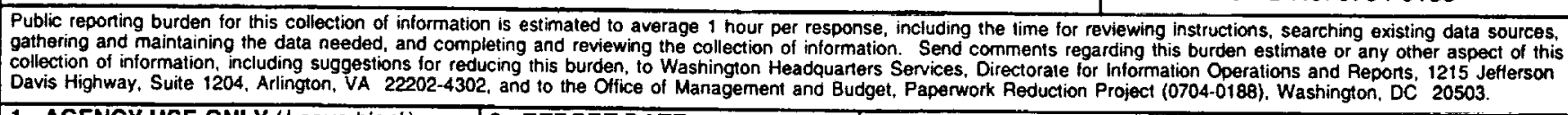 } \\
\hline 1. AGENCY USE ONLY (Leave blank) & \begin{tabular}{l|r|} 
k) & 2. REPOAT DATE \\
October 1998 \\
\end{tabular} & \multicolumn{3}{|c|}{$\begin{array}{r}\text { 3. REPORT TYPE AND DATES COVERED } \\
\text { Contractor Report }\end{array}$} \\
\hline \multicolumn{3}{|c|}{$\begin{array}{l}\text { 4. TITLE AND SUBTITLE } \\
\text { Nonlinear Comparison of High-Order and Optimized Finite-Difference Schemes }\end{array}$} & \multirow{2}{*}{\multicolumn{2}{|c|}{$\begin{array}{l}\text { 5. FUNDING NUMBERS } \\
\text { WU-523-36-13-00 } \\
\text { NCC } 3-531\end{array}$}} \\
\hline \multicolumn{3}{|l|}{$\begin{array}{l}\text { 6. AUTHOR(S) } \\
\text { R. Hixon }\end{array}$} & & \\
\hline \multicolumn{3}{|c|}{$\begin{array}{l}\text { 7. PERFORMING ORGANIZATION NAME(S) AND ADDRESS(ES) } \\
\text { Institute for Computational Mechanics in Propulsion } \\
22800 \text { Cedar Point Road } \\
\text { Cleveland, Ohio } 44142\end{array}$} & $\begin{array}{l}\text { 8. PE } \\
\text { PE } \\
\text { E }\end{array}$ & $\begin{array}{l}\text { ORMING ORGANIZATION } \\
\text { ORT NUMBER } \\
11393\end{array}$ \\
\hline \multicolumn{3}{|c|}{$\begin{array}{l}\text { 9. SPONSORING/MONITORING AGENCY NAME(S) AND ADDRESS(ES) } \\
\text { National Aeronautics and Space Administration } \\
\text { Lewis Research Center } \\
\text { Cleveland, Ohio } 44135-3191\end{array}$} & \multicolumn{2}{|c|}{$\begin{array}{l}\text { 10. SPONSORING/MONITORING } \\
\text { AGENCY REPORT NUMBER } \\
\text { NASA CR-1998-208670 } \\
\text { ICOMP-98-05 }\end{array}$} \\
\hline \multicolumn{5}{|c|}{$\begin{array}{l}\text { 11. SUPPLEMENTARY NOTES } \\
\text { R. Hixon, Institute for Computational Mechanics in Propulsion, NASA Lewis Research Center (work funded under } \\
\text { Cooperative Agreement NCC3-531). ICOMP Program Director, Dr. L.A. Povinelli, organization code 5000, (216) 433- } \\
5818 \text {. }\end{array}$} \\
\hline \multicolumn{3}{|c|}{$\begin{array}{l}\text { 12a. DISTRIBUTIONAVAILABILITY STATEMENT } \\
\text { Unclassified - Unlimited } \\
\text { Subject Categories: } 64,71 \text {, and } 34 \quad \text { Distribution: Nonstandard } \\
\text { This publication is available from the NASA Center for AeroSpace Information, (301) 621-0390. }\end{array}$} & \multicolumn{2}{|c|}{ 12b. DISTRIBUTION CODE } \\
\hline \multicolumn{5}{|c|}{ 13. ABSTRACT (Maximum 200 words) } \\
\hline \multicolumn{3}{|l|}{ 14. SUBJECT TERMS } & & $\begin{array}{l}\text { 15. NUMBER OF PAGES } \\
23\end{array}$ \\
\hline \multicolumn{3}{|c|}{ Computational aeroacoustics; Nonlinear; High-order; Optimized } & & 16. PRICE CODE \\
\hline $\begin{array}{l}\text { 17. SECURITY CLASSIFICATION } \\
\text { OF REPORT }\end{array}$ & $\begin{array}{l}\text { 18. SECUAITY CLASSIFICATION } \\
\text { OF THIS PAGE }\end{array}$ & $\begin{array}{l}\text { 19. SECUAITY CLASSIFICA } \\
\text { OF ABSTRACT }\end{array}$ & TTION & \begin{tabular}{|c|} 
A03 \\
20. LIMITATION OF ABSTRACT
\end{tabular} \\
\hline Unclassified & Unclassified & Unclassified & & \\
\hline
\end{tabular}


